\title{
Successful liver transplantation in babies under 1 year
}

\author{
S V Beath, G D Brook, D A Kelly, A J Cash, P McMaster, A D Mayer, J A C Buckels
}

\begin{abstract}
Objective-To review the outcome of liver transplantation in babies aged less than 1 year.

Design-Prospective evaluation of survival, clinical complications, and nutritional and developmental status before and one year after liver transplantation.

Setting-The Children's Hospital and Queen Elizabeth Hospital, Birmingham.

Subjects-All 25 babies who received liver transplantation from January 1989 to December 1992 were included. Median age was 9 months and median weight was $7 \cdot 0 \mathrm{~kg}$. Seven babies were assessed but were not given transplants because they died while on the waiting list (two) or had severe extrahepatic disease (five).
\end{abstract}

Results-24 babies had severe decompensated liver disease and 20 were severely malnourished despite nutritional support. Six babies received a whole liver graft and 19 received a reduction hepatectomy. Postoperative complications included primary nonfunction of the transplanted liver (one baby), hepatic artery thrombosis (two), biliary obstruction (seven), acute and chronic rejection (six), and sepsis (18). Three babies required a second transplant; all survived. Three babies, two of whom presented with fulminant hepatic failure, died. The overall actuarial survival rate (4 months to 4 years) is $88 \%$. Review at 12 months showed a dramatic improvement in growth $(p<0.001)$ and normal psychosocial development with good quality of life.

Conclusion-The improvement in survival rates and quality of life in this group of very sick babies is related not only to the development of reduction hepatectomy but also to advances in medical and nursing expertise. Early referral for liver transplantation is justified even if babies are critically ill.

\section{Introduction}

Liver transplantation is an established treatment for children with acute and chronic liver failure. ${ }^{1}$ Initially, liver transplantation in infants under 1 year or weighing less than $10 \mathrm{~kg}$ was associated with 1 year survival rates of $60 \%$, indicating greater technical problems in this age group than in older children in the same cohort and adults, of whom $75-80 \%$ survived. ${ }^{14}$ Furthermore, the shortage of paediatric donors meant that many babies were not considered for liver transplants or died while on the waiting list. The recent development of reduction hepatectomy ${ }^{48}$ has extended liver transplantation to many small infants who would otherwise have died waiting for a size matched graft. We prospectively evaluated the physical and psychosocial outcome of transplantation in 25 babies under 1 year with respect to preoperative condition, surgical technique, postoperative complications, and quality of life. The operation remains technically very demanding, but the awareness of the need for nutritional intervention, and specialised medical and nursing expertise, have contributed to a 1 year survival of $88 \%$, which surpasses previously published results. ${ }^{2} 5$ 7-11

\section{Patients and methods}

Between January 1989 and November 1992, 32 babies aged under 1 year were referred for assessment for liver transplantation. Five were excluded because of extrahepatic pathology that would have prevented successful transplantation: complex cardiac lesions (two babies) and gross neurological handicap secondary to hypoglycaemia induced by an inborn error of metabolism (three). Two babies died waiting for a donor liver. The indications for transplantation were biliary atresia (19), perinatally acquired fulminant hepatitis B (two), fulminant non-A non-B hepatitis (one), neonatal hepatitis (one), infantile haemachromatosis (one), and $\alpha 1$-antitrypsin deficiency (one). The median age was 9 months (range 7 weeks to 11.6 months) and the median weight was $7 \cdot 0 \mathrm{~kg}(4 \cdot 7-9 \cdot 8$ $\mathrm{kg}$ ). The infants (18 girls, seven boys) received either a whole liver graft or a reduction hepatectomy. ${ }^{6}$ Postoperative immunosuppression consisted of prednisolone (reducing dose from initial maximum of $2 \mathrm{mg} / \mathrm{kg} /$ day $)$, azathioprine $(2 \mathrm{mg} / \mathrm{kg} /$ day $)$, and cyclosporin (dose adjusted to achieve trough levels $150-300 \mathrm{ng} / \mathrm{ml}$ in whole blood assay). Prednisolone and azathioprine were discontinued three months and 12 months respectively after liver transplantation.

All patients' details were collected prospectively. Growth was assessed by two experienced auxologists who measured height (Holtain infant stadiometer), weight (Seca electronic scales, model 727), triceps skin fold (Holtain skinfold caliper, Holtain Ltd, Crosswell, Wales), and mid-arm circumference (non-stretch tape measure) within 30 days before and monthly after liver transplantation. To compare babies of different ages, all growth measurements have been expressed as a standard deviation score, which has been derived from a normal population-an SD of 0 is equivalent to the normal population median or 50th centile..$^{12-15}$ Developmental assessment was performed by a single examiner using the Griffiths mental development scales $^{16}$ at the same time or within a few days of anthropometry. Pre-transplant developmental assessments were not available on nine babies because of acute liver failure (four) and poor clinical condition (five).

\section{STATISTICAL METHODS}

The means of anthropometric and developmental variables before and after transplant were compared by the paired $t$ test. Actuarial survival was calculated by the Kaplan-Meier method. ${ }^{17}$

\section{Results}

Twenty four babies had evidence of severe decompensated liver disease at the time of transplant (table)
Ladywood Middleway,

$B M 71993 ; 307: 825-8$ 
Complications before and after liver transplantation in 25 babies under 1 year old

\begin{tabular}{lr}
\hline & $\begin{array}{r}\text { No of } \\
\text { babies }\end{array}$ \\
\hline Before transplant: & \\
Encephalopathy & 20 \\
Ascites & 17 \\
Varices & 17 \\
Cholangitis & 7 \\
Gastrointestinal bleed & 7 \\
Renal impairment & 6 \\
After transplant: & \\
Early: & \\
Primary non-function & 2 \\
Hepatic artery & \\
thrombosis & 2 \\
Acute rejection & 6 \\
Late: & \\
Sepsis & 17 \\
Seroconversion for & \\
cytomegalovirus & 8 \\
Biliary obstruction & 6 \\
\hline
\end{tabular}

and six required ventilatory support (four had multiorgan dysfunction including severe metabolic acidosis; two had acute encephalopathy). Nineteen were severely malnourished (fig 1) despite receiving an energy dense modular feed containing $110-160 \%$ of recommended daily energy allowance and $50-70 \%$ of total lipid intake as medium chain triglyceride. Sixteen babies $(64 \%)$ required feeding through a nasogastric tube and eight $(32 \%)$ needed parenteral nutrition for a median of six weeks (range 11 days to 12 weeks) before transplant. Motor scores were reduced (less than 80 ) in five babies in whom muscle bulk as measured by midarm muscle area was also reduced $(r=0.7, p=0.05)$. The other parameters of psychosocial development (motor skills, social behaviour, eye and hand coordination, language and speech ability, performance, and practical reasoning) were within the range of the reference population (80-120) before transplant (fig 2).

Twenty nine hepatic allografts, six whole and 23 reduced, were grafted in 25 patients. There were no significant differences in complications or outcome between the group receiving a whole graft and those receiving a reduced graft. The postoperative complications were grouped into early (0-14 days) and late (after 14 days) (table). Early complications included primary non-function of the transplanted liver in one baby, necessitating a second transplant, which was successful. Two babies developed hepatic artery thrombosis, one of whom was given two further transplants for recurrent thrombosis; the other spontaneously resolved. No deaths occurred after subsequent trans-

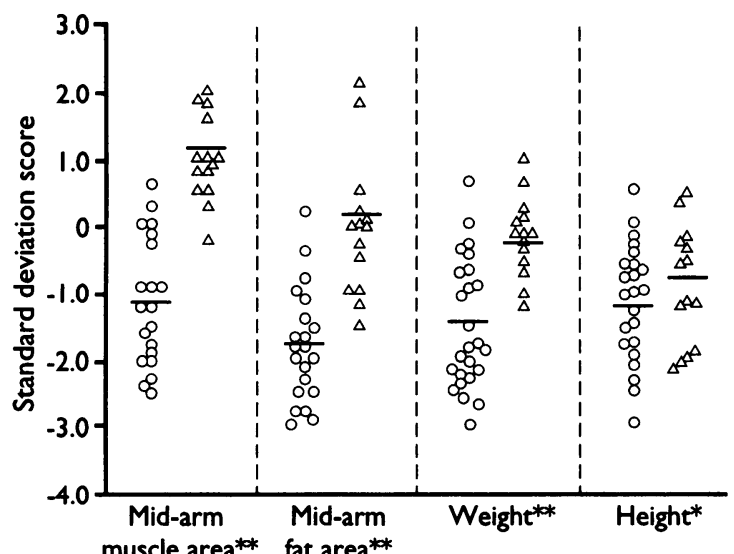

FIG 1-Anthropometry before $(O, n=25)$ and one year after $(\Delta, n=$ 14) liver transplantation. To compare babies of different ages, units were converted to a standard deviation score derived from a normal population. Some data missing for some children; data available for paired $t$ test in 14 patients; ${ }^{\star} p=0.05,{ }^{\star *} p=0.001$.

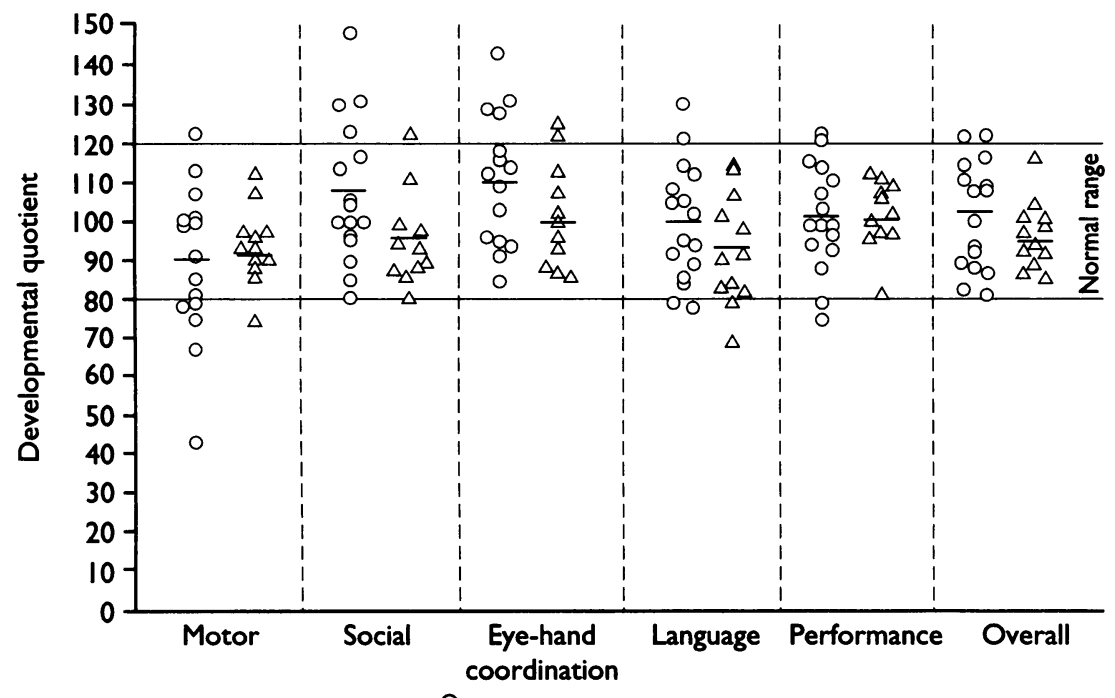

FIG 2-Developmental quotients before $(O, n=16)$ and one year after $(\Delta, n=12)$ liver transplantation. Data available for paired t test in 12 patients; no significant differences for any variable before and after transplant plants. Two babies died within 72 hours of operation because of overwhelming fungal sepsis in one and Gram negative sepsis in the other; a third baby with acute liver failure suffered irreversible brain stem compression despite a technically successful transplant. There were no subsequent deaths, and the current overall survival was $88 \%$, with follow up from four to 48 months (fig 3 ).

Intensive care was prolonged beyond five days in six babies because of dependence on mechanical ventilation, which was related to severe malnutrition in three (mean weight SD score $-2 \cdot 34$, mean height SD score $-2 \cdot 42$ ) and haemodynamic instability caused by sepsis in the other three. Most babies resumed enteral feeding within seven days of receiving the transplant, although 10 required parenteral nutrition for 5-24 days and nine continued nocturnal nasogastric tube feeding for 6-12 months for behavioural feeding problems.

Acute rejection occurred in six babies between days 5 and 21 and was successfully treated with a three day course of methylprednisolone $(20-40 \mathrm{mg} / \mathrm{kg} /$ day intravenously). One of these babies developed early chronic rejection, which was treated successfully with FK506 (Fujisawa GmbH, Munich).

Systemic bacterial infection was a major complication affecting three quarters of the infants in the first $\mathbf{1 4}$ days after transplant but causing death in only one child. Another child died of fungal infection.

Late complications included biliary obstruction or leak, or both, which affected seven patients, necessitating surgical reconstruction in five. Bacteria were cultured from bile in five of the cases (four were faecal organisms, one was Pseudomonas aeruginosa). After a modification of surgical technique that reduced the risk of ischaemia to the donor bile $\operatorname{duct}^{6}$ and a discontinuation of the use of indwelling biliary drains, biliary complications in this series reduced from $50 \%$ in the first 10 transplants to $13 \%$ in the last 15 .

Cytomegalovirus and Epstein-Barr virus infections were common late complications. Twelve $(53 \%)$ of the surviving infants had IgM cytomegalovirus antibodies and nine (40\%) had Epstein-Barr virus capsid antibodies within 12 months of transplantation. Four babies had abnormal results on liver function tests and symptomatic cytomegalovirus infection with ascites and neutropenia four to eight weeks after transplantation despite prophylaxis with acyclovir. They were successfully treated with cytomegalovirus hyperimmune globulin and ganciclovir. The remainder developed a mild anaemia only and received no specific treatment other than reduction in immunosuppression. Epstein-Barr virus infection was associated with coryzal symptoms and anaemia but no progression to an immunoproliferative state was observed.

Babies were discharged three to 16 weeks (median six weeks) after operation, and there was a trend towards longer hospital stay in those who were more malnourished $(p=0.08)$. Only six grafts were whole organs and no significant differences were observed in the number or type of postoperative complications compared with reduction transplants.

Detailed review at 12 months in 14 children showed dramatic improvements in all four anthropometric indices, especially for mid-arm muscle area and midarm fat area $(\mathrm{p}=<0.001)$, indicating a rapid return to normal body habitus and catch up growth in height and weight (fig 2). In nine children followed up for 24 months, weight $(p=<0.01)$ and height $(p=<0.05)$ continued to improve significantly, and mid-arm muscle area and mid-arm fat area were maintained within normal range.

Development was assessed after liver transplant in 11 children (preoperative developmental assessments were not available in one of the children who had detailed anthropometry, and postoperative assessment 


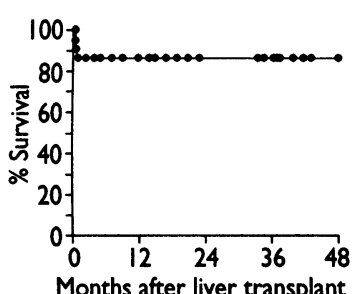

Months after liver transplant

FIG 3-Actuarial survival in 25 babies who received liver transplantation before 12 months of age. Intervals of 12 months were used to calculate probability of survival. Cumulative probability of survival remain at $0.88(88 \%)$ because no deaths have occurred beyond seven days after operation in this group so far was not completed in two because of poor cooperation). Improvement occurred in those babies who had delayed motor development before transplant (fig 3). Two babies who achieved exceptionally high scores for eye-hand coordination, social abilities, and language abilities before transplant regressed to the normal range after transplant (fig 3). Most infants scored within the normal range before and after transplant for all five developmental variables, and no significant differences in scores emerged by 12 months after operation. All children enjoy normal quality of life according to their parents' observations and attend either playgroups or nursery school.

\section{Discussion}

The physiology and anatomy of babies under 1 year produce unique management problems during liver transplantation which differentiate them from adults and older children. Respiratory and ventilation problems occurred in a quarter of babies. These were related to reduced lung compliance and functional residual capacity in infancy, which were compromised by abdominal splinting secondary to the transplanted liver. ${ }^{18}$ In this series the physiological problems were complicated by malnutrition or septic shock in six infants who required prolonged ventilation. This compares with a prolonged ventilation requirement of only $10 \%$ in children aged over 1 year (unpublished observation).

As energy requirements are higher in infancy than at any other time of life, ${ }^{1920}$ malnutrition secondary to chronic liver disease is an inevitable development, and this was present in $80 \%$ of the group. Although malnutrition did not seem to affect mortality in this series, others have shown a relation with between malnutrition and mortality after liver transplantation. $^{21}$ Thus, the aggressive approach to nutritional intervention before transplant with early nasogastric tube feeding or parenteral nutrition, or both, if energy intake was suboptimal may have been an important factor in improving survival. The combination of severe liver disease and malnutrition, which necessitated nasogastric tube feeding and special diets, led to behavioural feeding problems in a third of babies after transplant, which resolved postoperatively after a 6-12 month programme of oral stimulation under the supervision of a clinical psychologist. ${ }^{22}$

In common with other groups, ${ }^{25910}$ sepsis $(75 \%)$ was the most common postoperative problem. To minimise septic episodes, steroid doses were reduced from day 5 after transplant and discontinued completely by three months. Azathioprine was also reduced or discontinued if neutropenia or infection developed. Despite this relatively mild immunosuppressive regimen neither acute nor chronic rejection was a major problem, affecting only $24 \%$ of babies compared with a rejection rate of $65 \%$ in older children reported from other centres. ${ }^{9}$ The immunological immaturity of babies may spare them from serious rejection crises. ${ }^{23}$

Hepatic artery thrombosis has been reported to be a major cause of morbidity in a quarter of babies after liver transplantation. ${ }^{2}$ Only $8 \%$ of babies in our series developed hepatic artery thrombosis, which may be related to the larger vasculature of reduced adult donor livers and maintenance of the venous packed cell volume below $35 \%{ }^{24}$ The avoidance of hepatic artery thrombosis and low incidence of rejection have contributed to a much lower rate of retransplantation$12 \%$ compared with $30 \%$ in other reports. ${ }^{210}$

Many series have reported a high incidence of biliary problems, which included leaks or strictures $\left(25 \%{ }^{2}\right)$ and sepsis $\left(65 \% \%^{4}\right)$. After a modification of surgical technique, ${ }^{6}$ biliary complications in this series reduced from $50 \%$ to $13 \%$.
Liver transplantation in infancy is costly in terms of health care resources and can be justified only if the long term outcome is good. We have assessed outcome by measuring not only actuarial survival but also by monitoring growth and neuropsychosocial development, which reflects quality of life. Our initial results showed that these infants returned to their growth potential within 12 months despite early malnutrition (fig 2). Catch up growth was most obvious in weight, mid-arm muscle area, and mid-arm fat area. Longitudinal growth responds more slowly to changes in environmental circumstances and most other series do not show catch up growth until at least 18 months after liver transplantation. ${ }^{102526}$ We have shown significant catch up growth in longitudinal growth within 12 months, which may be due to our practice of discontinuing steroids by three months after transplantation. At 24 months after liver transplant the catch up in longitudinal growth was still evident, although growth rate in mid-arm muscle area and mid-arm fat area stabilised at the median for the reference population.

There are no other comparable studies of developmental outcome in this age group, although Stewart et al compared neurodevelopmental outcome in children aged 4.6 years and older who had received liver transplants and matched children with cystic fibrosis. ${ }^{26}$ These older children had lower scores in areas of learning and memory, abstraction, and visual spatial function, but these results could reflect the effect of chronic liver disease before transplantation rather than transplantation itself. Liver transplantation in early infancy may be associated with better long term developmental outcome as, apart from reduced motor function related to hypotonia and reduced muscle bulk, the psychosocial development of the babies was within normal limits before and after the transplant operation. After the operation, motor scores recovered and, apart from two babies who had achieved exceptionally high scores for eye-hand coordination, social abilities, and language abilities before transplant, developmental progress was well maintained for most infants for all five variables studied. This is the first report to document preservation of normal development in infants despite a stressful operation and prolonged hospitalisation. Long term follow up is important ${ }^{26}$ and is being undertaken.

Before the successful development of liver transplantation, infants with hepatic failure in the first year of life faced almost certain death. ${ }^{27}$ We report the beneficial effects of the introduction of reduction hepatectomy, greater surgical experience, specialisa-

\begin{tabular}{l} 
Clinical implications \\
\hline - Survival rate in children under 1 year given \\
liver transplants was $88 \%$ after one year in this \\
series of 25 patients \\
- Physiological problems in this age group can \\
be complicated by malnutrition secondary to \\
chronic liver disease \\
- Sepsis, the most common postoperative \\
problem, can be treated by reducing steroid \\
doses from day 5 after transplantation and discon- \\
tinuing steroids completely by three months \\
- Neither acute nor chronic rejection was a \\
major problem; nor was hepatic artery throm- \\
bosis. Biliary complications were reduced by a \\
modification of surgical technique \\
- These infants had returned to their growth \\
potential within 12 months despite early mal- \\
nutrition and maintained normal psychosocial \\
development
\end{tabular}


tion of medical and nursing care, and nutritional intervention, which have improved the survival rate in this most challenging group of patients from $60 \%$ to $88 \%$. This has been achieved with good quality of life despite a high perioperative morbidity and the greater technical difficulties related to the small size of the patient.

We acknowledge the dedication of the nursing staff at the Children's Hospital, and the Queen Elizabeth Hospital, whose skill brought these children back to health. We thank Dr Gill Harris, clinical psychologist, for her advice.

1 Whitington PF, Balistreri W. Liver transplantation in pediatrics: indications, contraindications, and pretransplant management. $f$ Pediatrics 1991;118: 169-77.

2 Esquivel C, Koneru B, Karrer F, Todo S, Iwatsuki S, Gordon R, et al. Liver transplantation before 1 year of age. $\mathcal{F}$ Pediatr 1987;110:545-8.

3 Chiyende J, Mowat AP. Liver transplantation. Arch Dis Child 1992;67:1124-7.

4 Otte JB, deVille de Goyet J, Sokal E, Alberti D, Moulin D, de Hemptinne B, et al. Size reduction of the donor liver is a safe way to alleviate the shortage of size matched organs in pediatric liver transplantation. Ann Surg 1990;211: $146-57$.

5 Ryckman FC, Flake AW, Fisher RA, Tchervenkov JI, Pedersen SM Balistreri WF, et al. Segmental orthotopic hepatic transplantation as a mean to improve patient survival and waiting-list mortality. $f$ Pediatr Surg 1991;26:422-7.

6 Badger II, Czerniak A, Beath S, Tisone G, Deakin M, Sherlock DJ, et al. Hepatic transplantation in children using reduced size allografts. Br $\mathcal{F}$ Surg 1992;79:47-9.

7 Kalayoglu M, Stratta RJ, Sollinger HW, Hoffman RM, D'Alessandro AM, Pirsch JD, et al. Liver transplantation in infants and children. $f$ Pediatr Surg 1989;24:70-6.

8 Houssin D, Soubrane O, Boillot O, Dousset B, Ozier Y, Devictor D, et al. Orthotopic liver transplantation with reduced size graft: an ideal compromise in pediatrics? Surgery 1992;111:532-42.

9 Salt A, Noble-Jamieson G, Barnes ND, Mowat AP, Rolles K, Jamieson N, et al. Liver transplantation in 100 children: Cambridge and King's College Hospital series. BMf 1992;304:416-21.

10 Sokal EM, Veyckemans F, de Ville de Goyet J, Moulin D, Van Hoorebeeck N Alberti $\mathrm{D}$, et al. Liver transplants in children less than 1 year of age. fPediatr 1990;117:205-10
11 Lynch SV, Akiyama T, Ong TH, Pillay SP, Balderson GA, Matsunami H, et al. Transplantation in children with biliary atresia. Transplant Proc 1992;24:186-8.

12 Sann L, Durand M, Picard J, Lasney, Bethenod M. Arm fat and muscle areas in infancy. Arch dis Child 1988;63:256-60.

13 Frisancho AR. New norms of upper limb fat and muscle areas for assessment of nutritional status. Am f Clin Nutr 1981;34:2540-5.

14 Jordan MD. The CDC anthropometric software package. Version 3. Atlanta Centers for Disease Control, 1987.

15 Smith DE, Booth IW. Nutritional assessment of children: guidelines on collecting and interpreting anthropometric data. f Human Nutr Diet. 1989;2:217-24.

16 Griffiths Mental Development Scales. High Wycombe. The Test Agency, 1986.

17 Pocock SJ, ed Clinical trials: a practical approach. Chichester; John Wiley, 1983:222-4.

18 Morgan GE, Mikhail MS. Pediatric anesthesia. In: Morgan GE, Mikhail MS, eds. Clinical anesthesiology. London: Prentice Hall International, 1992: 630-6.

19 Kaufman SS, Murray ND, Wood RP, Shaw BW, Vanderhoef JA. Nutritional support for the infant with extrahepatic biliary atresia. $f$ Pediatr 1987;110 679-86.

20 Brooke OG. Energy needs in infancy. In: Foman SJ, Heird WC, eds. Energy and protein needs during infancy. London: Academic Press, 1986:3-17.

1 Moukarzel AA, Najm I, Vargas J, McDiarmid SV, Busuttil RW, Ament ME Effect of nutritional status on outcome of orthotopic liver transplantation in pediatric patients. Transplant Proc 1990;22:1560-3.

22 Harris G, Booth IW. Feeding problems and eating disorders in children and adolescents. In: Cooper PJ, Stein A, eds. Monographs in clinical pediatrics. Vols. Reading: Harwood Academic Publishers, 1992:61-84.

23 Miyawaki T, Moriya N, Nagaoki T, Taniguchi N. Maturation of B-cell differentiation ability and $T$-cell regulatory function in infancy and childhood. Immunol Rev 1981;57:61-87.

24 Buckels JAC, Tisone G, Gunsen BK, McMaster P. Low haematocrit reduces hepatic artery thromobosis after liver transplantation. Transplant Proc 1989;21:2460-1.

25 Chin SE, Shepherd RW, Cleghorn GJ, Patrick MK, Javorsky G, Frangoulis E, et al. Survival, growth and quality of life in children after orthotopic liver transplantation: a 5 year experience. $\mathcal{F}$ Paediatr Child Health 1991;27:380-5.

26 Stewart SM, Uauy R, Waller DA, Kennard BD, Benser M, Andrews WS Mental and motor development, social competence, and growth one year after successful pediatric liver transplantation. $\mathcal{F}$ Pediatr 1989;114:574-81.

27 Malatack JJ, Schaid DJ, Urbach AH, Gartner JC, Zitelli BJ, Rockette H, et al. Choosing a pediatric recipient for orthotopic liver transplantation. 9 Pediat 1987;111:479-89.

(Accepted 12 August 1993)

\title{
Radioiodine treatment of multinodular non-toxic goitre
}

\author{
Birte Nygaard, Laszlo Hegedüs, Morten Gervil, Henrik Hjalgrim, Peter Søe-Jensen, \\ Jens Mølholm Hansen
}

\section{Departments of Internal \\ Medicine and \\ Endocrinology and \\ Ultrasound, Herlev \\ University Hospital, \\ DK 2730 Herlev, Denmark \\ Birte Nygaard, registrar \\ Morten Gervil, registrar \\ Henrik Hjalgrim, registrar \\ Peter Søe-Jensen, medical student \\ Jens Mølholm Hansen, \\ consultant physician}

\section{Department of Internal \\ Medicine and \\ Endocrinology, Odense \\ University Hospital, \\ DK 5000 Odense C, \\ Denmark \\ Laszlo Hegedüs, consultant}

physician

Correspondence and reprint

requests to:

Dr Laszlo Hegedüs,

Department of Internal

Medicine and

Endocrinology $M$,

Odense University Hospital,

DK-5000 Odense C,

Denmark.

BMf 1993;307:828-32

\section{Abstract}

Objective-To investigate the long term effect of radioactive iodine on thyroid function and size in patients with non-toxic multinodular goitre.

Design-Consecutive patients with multinodular non-toxic goitre selected for radioactive iodine treatment and followed for a minimum of 12 months (median 48 months) after an intended dose of 3. $7 \mathrm{MBq} / \mathrm{g}$ thyroid tissue corrected to a $100 \%$ uptake of iodine-131 in 24 hours.

Patients -69 patients with a growing multinodular non-toxic goitre causing local compression symptoms or cosmetic inconveniences. The treatment was chosen because of a high operative risk, previous thyroidectomy, or refusal to be operated on.

Main outcome measurements-Standard thyroid function variables and ultrasonically determined thyroid volume before treatment as well as $1,2,3,6$, and 12 months after treatment and then once a year.

Results -56 patients were treated with a single dose of ${ }^{131} I, 12$ with two doses, and one with four doses. In 45 patients treated with one dose and remaining euthyroid the median thyroid volume was reduced from 73 (interquartile range 50-106) $\mathrm{ml}$ to 29 (23-48) $\mathrm{ml}$ at 24 months in the 39 patients in whom this was measured during follow up. The median reduction was $40(22-48) \mathrm{ml}(60 \%$ reduction, $\mathbf{p}<0.0001$ ), half of which occurred within three months. Patients treated with two doses as well as those developing hypothyroidism and hyperthyroidism had a significant reduction in thyroid volume. Eleven patients developed hypothyroidism (cumulative five year risk $22 \%, 95 \%$ confidence interval $4 \cdot 8 \%$ to $38 \cdot 4 \%$ ). Side effects were few: three cases of hyperthyroidism and two cases of radiation thyroiditis. Only one patient was dissatisfied with the result; she was referred for operation six months after treatment.

Conclusions-A substantial reduction in thyroid volume accompanied by a low incidence of hypothyroidism and few side effects makes the use of radioactive iodine an attractive alternative to surgery in selected cases of non-toxic multinodular goitre.

\section{Introduction}

The yearly growth rate of non-toxic multinodular goitres has been estimated at $10-20 \% .^{1}$ Suppressive treatment with thyroxine or triiodothyronine reduces the thyroid volume in diffuse non-toxic goitre by up to $30 \%,{ }^{2}$ but it is disputed whether such an effect can be achieved in multinodular glands. ${ }^{134}$ The growing nodular non-toxic goitre is traditionally treated by subtotal thyroidectomy.

At least $10 \%$ of patients have a recurrence after subtotal thyroidectomy for non-toxic multinodular goitre. ${ }^{56}$ In these patients, as well as in others with a high surgical risk, a non-operative reduction in thyroid size would be desirable. Treatment of hyperthyroidism with radioactive iodine $\left({ }^{131} \mathrm{I}\right)$ is well accepted and usually results in a substantial decrease in the size of the thyroid. ${ }^{78}$ The possibility of ${ }^{131} I$ treatment of non- 